\title{
Gambaran Pengalaman Pembelajaran Blended Learning Mahasiswa Semester I menggunakan Google Classroom
}

\author{
Rahmadika Akbar, $\mathrm{R}^{1}$, Anissa, $\mathrm{M}^{2}$, Ayu Hamama Pitra, $\mathrm{D}^{3}$, Anggraini $\mathrm{D}^{4}$, Hasni $\mathrm{D}^{5}$ \\ ${ }^{1}$ Bagian Pendidikan Kedokteran dan Medical Education Unit, Fakultas Kedokteran, Universitas Baiturrahmah, \\ Padang, Indonesia \\ Email : restiakbar@fk.unbrah.ac.id \\ ${ }^{2}$ Bagian Psikiatri dan Medical Education Unit, Fakultas Kedokteran, Universitas Baiturrahmah, Padang, \\ Indonesia \\ ${ }^{3}$ Bagian Neurologi dan Medical Education Unit, Fakultas Kedokteran, Universitas Baiturrahmah, Padang, \\ Indonesia \\ ${ }^{4}$ Bagian Patologi Klinik dan Medical Education Unit, Fakultas Kedokteran, Universitas Baiturrahmah, Padang, \\ Indonesia \\ ${ }^{5}$ Bagian Farmakologi dan Medical Education Unit, Fakultas Kedokteran, Universitas Baiturrahmah, Padang, \\ Indonesia
}

\begin{abstract}
Abstrak
Latar Belakang: Perkembangan teknologi informasi pada era revolusi 4.0 juga berpengaruh pada pendidikan. Pendidikan tinggi dituntut untuk mengembangkan kurikulum yang berbasis literasi digital dan literasi teknologi. Penggunaan blended learning mengkombinasikan metode tatap muka dengan google classroom pada modul pengantar pembelajaran kedokteran. Tujuan penelitian ini untuk mengetahui pengalaman pembelajaran mahasiswa menggunakan blended learning. Metode: Penelitian ini merupakan penelitian deskriptif dengan rancangan potong lintang. Sampel penelitian adalah mahasiswa semester pertama Fakultas Kedokteran universitas Baiturrahmah. Data dikumpulkan melalui kuisioner online menggunakan google form. Hasil: Jumlah responden 56 mahasiswa. Sebanyak 83.9\% mahasiswa sudah familiar dengan istilah e-learning atau blended learning, 92.9\% menyatakan tidak mengalami kesulitan saat menggunakan google classroom. Sebanyak 92,9\% mahasiswa merekomendasikan google classroom sebagai media yang cukup efektif. Kesimpulan: manfaat blended learning dapat dirasakan oleh mahasiswa, media menyampaikan sumber pembelajaran dan media diskusi dengan mahasiswa serta memeriksa hasil tugas mahasiswa dengan cepat, serta meningkatkan kedisiplinan mahasiswa.
\end{abstract}

Katakunci — blended learning, e-learning, google classroom, revolusi 4.0

\begin{abstract}
Background:The development of technology information in the 4.0 revolution era also affected to education. Higher education is demanded to develop curriculum based on digital literacy and technology literacy. The use of blended learning combines face-to-face methods with Google classroom in the Modul Pengantar Pembelajaran Kedokteran.Objective of this study is to find out at the learning experiences of students using blended learning. Methods: This is descriptivestudy with cross sectional design. The study sample was first semester students at the Faculty of Medicine at Baiturrahmah University. Data collected through online questionnaire using Google form. Results: The number of respondents was 56 students. As many as $83.9 \%$ of students are familiar with the term e-learning or blended learning, 92.9\% stated they did not experience difficulties when using google classroom, as many as $92.9 \%$ of students recommend google classroom as an effective media to e-learning. Conclusion: the benefits of blended learning can be felt by students, the media deliver learning resources and discussion with students and examine the results of student assignments quickly, and improve student discipline.
\end{abstract}

Keywords-blended learning, e-learning, google classroom, revolusi 4.0

Health \& Medical Journal 


\section{Pendahuluan}

Pendidikan tinggi saat ini dituntut untuk mengembangkan kurikulum di era industri 4.0 yang disesuaikan dengan perkembangan zaman. Pengembangan yang dimaksud yaitu berbagai literasi yang harus dikuasai oleh mahasiswa maupun dosen. Salah satunya adalah literasi digital dan literasi teknologi. Pada literasi digital dan literasi teknologi implikasinya adalah dengan adanya elearning. E-learning merupakan suatu sistem atau konsep pendidikan yang menfaatkan teknologi dan informasi dalam proses pembelajaran dan pengajaran. ${ }^{1,2}$

Sistem pembelajaran secara $e$-Learning harus diimbangi dengan peningkatan kompetensi dosen. Mahasiswa yang dihadapi dosen saat ini adalah mahasiswa generasi milenial dan generasi $\mathrm{Z}$, oleh karena itu dosen harus meningkatkan kompetensi keilmuan serta melakukan inovasi metode pembelajaran. ${ }^{3,4}$ Pembelajaran di fakultas kedokteran dengan memanfaatkan e-learning merupakan salah satu bentuk usaha menyediakan berbagai sumber pembelajaran selain di kelas. ${ }^{3}$

Mahasiswa dapat mengakses sumber pembelaran dimana saja dan kapan saja untuk melengkapi pembelajaran tatap muka. Pada metode ini disebut blended learning, yaitu sebuah kemudahan pembelajaran dengan menggabungkan pengajaran tatap muka dengan pengajaran online. Untuk beralih dari model pembelajaran tatap muka atau pertemuan secara langsung, lalu berubah menjadi daring perlu biaya yang tidak sedikit menyangkut pengembangan kemampuan pada dosen dan tersedianya sarana dan prasarana pendukung. ${ }^{1,5,6}$

Pada modul pengantar pembelajaran kedokteran, digabungkan metode tatap muka dan e-learning atau yang kita kenal sebagai blended learning. Media yang digunakan adalah google classroom, yang mudah diakses. Blended learning bukan berarti menggantikan peran dosen, tetapi menjembati mahasiswa yang merupakan generasi $\mathrm{Z}$, yang sudah melek dengan perkembangan teknolog informasi. Metode ini diharapkan dapat membuat mahsiswa tertarik dan memudahkan mahasiswa mengakses pembelajaran dimana saja dan kapan saja. ${ }^{7,8}$

Google classroom atau ruang kelas Google merupakan serambi pembelajaran yang diperuntukkan untuk membagikan tugas dan pengumpulan tugas sehingga mengurangi penggunaan kertas terutama dimanfaatkan untuk membagikan bahan kuliah dan pengumpulan tugas. Untuk suatu modul bisa bekerjasama dengan beberapa orang dosen. Dosen yang menjadi admin disebut sebagai teacher, dan dosen lain yang bergabung dan bertindak sebagai pemeriksa tugas atau membagikan bahan pembelajaran disebut dengan co-teacher. ${ }^{3,5}$

Google classroom memiliki kelebihan dan kekurangan. Kelebihannya bisa online, mahasiswa bisa mengakses dari mana saja. Proses pengaturan kelas yang cukup mudah dan bisa langsung mengelompokkan tugas sesuai dengan sesi pembelajaran serta meningkatkan kerjasama dan komunikasi baik antar dosen maupun mahasiswa, penyimpanan data terpusat, tugas mahasiswa bisa disimpan langsung ke google drive. Sedangkan kekurangannya perlu password untuk masuk di setiap kelas. Pengguna juga membutuhkan jaringan internet yang stabil agar pengiriman tugas lancar.

Tujuan penelitian ini adalah untuk mengetahui pengalaman pembelajaran mahasiswa mengunakan google classroom pada modul pengantar pembelajaran kedokteran.

\section{Metode Penelitian}

Penelitian ini merupakan penelitian deskriptif dengan rancangan potong lintang.

Email : heme@unbrah.ac.id 
Sampel penelitian adalah mahasiswa yang mengikuti modul pengantar pembelajaran kedokteran, dengan kuesioner evaluasi kegiatan. Sampel penelitian berjumlah 56 orang dengan teknik consecutive sampling. Mahasiswa dibagikan kuesioner secara online mengunakan google form. Kuesioner berisi pertanyaan dan pernyataan mengenai pengalamannya menggunakan google classroom, kendala dan keuntungan dari penggunaan google classroom. Untuk melihat persepsi dosen yang terlibat dalam proses pembelajaran modul, digunakan kuesioner mengenai pemakaian dan efektivitasnya.

\section{HASIL}

Dari 150 mahasiswa semester 1 yang mengisi kuesioner sebanyak 56 orang, yang sudah mencukupi jumlah sampel minimal. Sebanyak $83.9 \%$ mahasiswa sudah familiar dengan istilah e-learning atau blended learning, $92.9 \%$ menyatakan tidak mengalami kesulitan saat menggunakan google classroom.

Apakah Saudara mengalami kesulitan menggunakan google classroom 56 responses

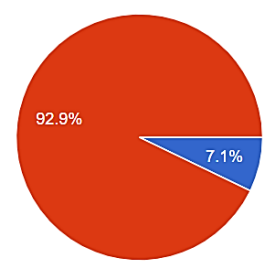

$$
\text { Ya }
$$

Gambar 1. Kesulitan dalam menggunakan google classroom

Dengan munculnya kendala seperti yang dikemukakan mahasiswa di atas, maka kami menanyakan apakah mereka merekomendasikan penggunaan google classroom sebagai media yang diginakan untuk blended learning? Sebanyak 92,9\% mahasiswa merekomendasikan google classroom sebagai media yang cukup efektif. Menindaklanjuti pertanyaan dan jawaban maahasiswa yang merekomendasikan goggle classroom sebagai media blended, kami menanyakan untuk memastikan, apakah mahasiswa terbantu dengan media ini dibandingkan harus mengumpulkan tugas dicatat atau di cetak menggunakan kertas. Semua sampel menyetujui kemudahan yang dapat mereka rasakan dalam pengumpulan tugas.

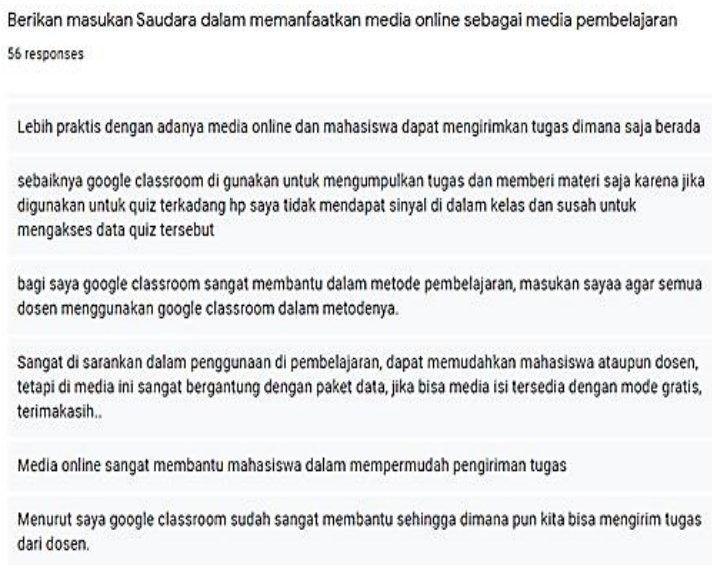

Gambar 2. Masukan dari mahasiswa mengenai pemanfaatan media online sebagai media pembelajaran

Untuk penggunaan google classroom sesuai dengan rekomendasi mahasiswa, kami meminta mereka memberikan masukan untuk efektivitas pembelajaran dengan $e$ learning: mahasiswa menyukai pembelajaran menggunakan google classroom tetapi mereka kesulitan dengan sinyal wifi yang tidak stabil, google classroom yang diatur waktu pengumpulan tugasnya membuat mahasiswa menjadi lebih disiplin, karena bila terlambat mengumpulkan tugas, maka akan langsung dilabeli "done late" sehingga mahasiswa bisa menilai diri sendiri dan menantang diri mereka agar pengumpulan tugas lebih disiplin lagi.

Membandingkan dengan kuesioner pengalaman pembelajaran dari mahasiswa, maka peneliti sebagai administrator pada google classroom di modul ini, yang meminta co-teacher untuk memberikan pandangannya terhadap google classroom sebagai media blended learning. Co-teacher yang terlibat di dalam modul ini sebanyak 7 orang, dan yang memberikan masukannya 
adalah 5 orang. Sebagian besar sudah mengenal mengenai blended learning. Yang terlibat di dalam modul ini belum pernah mengikuti pelatihan blended learning.

Berdasarkan pandangan dosen yang terlibat penerapan blended learning dalam kurikulum sebanyak $<30 \%$. Beberapa dosen sebagai co-teacher juga merasakan manfaat penggunaan google classroom. Akan tetapi untuk menjadi course manager masih mengalami kesulitan untuk menyiapkan materi pembelajaran yang dikirimkan melalui google classroom.

Dosen menilai mahasiswa siap mengikuti dalam pembelajaran bauran atau blended learning. Dengan memberikan tutorial sebelumnya menggunakan google classroom. Beberapa dosen bahkan sudah menggunakan media lain sebagai media $e$ learning yaitu trello, flipgrid, poll everywhere explianevery. Sebagai coteacher, dosen merekomendasikan untuk menggunakan google classroom. Dosen juga menilai pembelajaran blended learning masih harus disosialisasikan baik untuk dosen maupun mahasiswa sehingga implementasi untuk kurikulum lebih sesuai dengan porsinya.

\section{Pembahasan}

Blended learning dapat diterima baik oleh dosen maupun oleh mahasiswa. Metode pembelajaran yang menggabungkan tatap muka dan juga berbagai media untuk $e$ learning. Media yang dapat digunakan bisa Moodle, Edmoodo, survey monkey, ataupun google classroom.

Email : heme@unbrah.ac.id

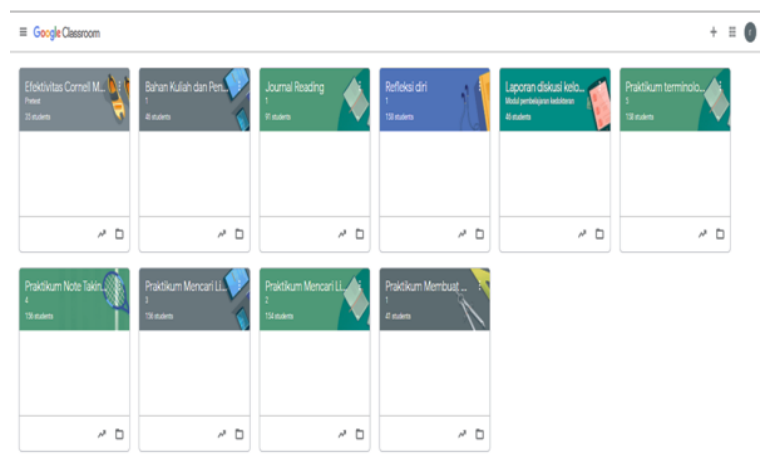

Gambar 3. Sesi kelas di google classroom pada modul pengantar pembelajaran kedokteran

Pada gambar 3. Tampak beberapa sesi kelas, di setiap kelas terdapat judulnya. Pada setiap sesi kelas, dosen bisa memberikan materi, bahan bacaan, link Youtube, memberikan kuis, pengumuman dan pengumpulan tugas. ${ }^{5}$ Pada pembelajaran online, dosen dapat melihat perhatian peserta didik berdasarkan kedisiplinan dalam pengumpulan tugas. ${ }^{7}$

Penelitian ini memberikan gambaran penting mengenai perkembangan teknologi informasi yang memiliki pengaruh terhadap kurikulum dan metode pembelajaran. Mahasiswa tahun pertama yang modul pertamanya merupakan modul pengantar pembelajaran kedokteran, yang terdiri dari berbagai metode pembelajaran dan pengajaran yaitu diskusi tutorial, kuliah pengantar, dan praktikum.

Terdapat 3 aspek penting pada e-learning yaitu kemudahan dalam penggunaannya, cost effective dan kepuasan dari mahasiswa. ${ }^{5,7,9}$ Dari pertanyaan-pertanyaan yang diajukan mengenai pengalaman mengunakan google classroom, mahasiswa pada umumnya menyatakan dapat mengikuti dan dengan mudah menggunakannya. Untuk cost effective dirasakan cukup, karena bila dibandingkan mereka harus mencetak tugas mereka tentu mereka harus mengeluarkan biaya untuk biaya cetak. Sedangkan untuk kepuasan, mahasiswa merasakan puas menggunakan google classroom.

Salah satu pengaruh positif dengan menggunakan blended learning adalah peningkatan dalam self directed learning. 
Mahasiswa dapat menilai diri mereka sendiri mengenai kedisiplinan dalam pengumpulan tugas, sehingga mereka lebih memaksimalkan kemampuannya untuk mengatur waktu. 3,510

\section{KESIMPULAN DAN SARAN}

Berdasarkan analisis hasil penelitian dan pembahasan dapat disimpulkan bahwa manfaat blended learning dapat dirasakan oleh mahasiswa, dengan sebelumnya memberikan arahan dan tutorial bagaimana cara menggunkan media e-learning dalam hal ini google classroom. Mahasiswa lebih disiplin dalam pengumpulan tugas dan juga paper less. Dari dosen dirasakan ada manfaatnya sebagai media menyampaikan sumber pembelajaran dan media diskusi dengan mahasiswa serta memeriksa hasil tugas mahasiswa dengan cepat. Dari penelitian ini didapatkan juga pemanfaatan media lebih memudahkan mahasiswa dan perlu pengembangan media lain yang memiliki kapasitas yang lebih besar. Untuk penelitian selanjutnya dapat digali lebih lanjut mengenai hubungan self directed learning dengan penggunaan blended learning, dan perbandingan dengan berbagai media e-learning lainnya.

\section{DAFTAR Pustaka}

[1] Direktorat Jenderal Pembelajaran dan Kemahasiswaan Kemeristekdikti. Panduan Penyusunan Kurikulum Pendidkan Tinggi di Era Industri 4.0. 2019

[2] Angraini MR, Muharini R, Lestari I. Penerapan blended learning berbasis edmodo. 2018; 1-12.

[3] Gillette C, Rudolph M, Kimble C, et al. A MetaAnalysis of Outcomes Comparing Flipped Classroom and Lecture. 2018; 82: 433-440.

[4] Liu Q, Peng W, Zhang F, et al. The Effectiveness of Blended Learning in Health Professions: Systematic Review and Meta-Analysis. Corresponding Author: $18 . \quad$ DOI: 10.2196/jmir.4807.

[5] Dash S. Article Google Classroom as a Learning Management System to Teach Biochemistry in a Medical School. 2016; 1-4.

[6] Micheal S. Blended learning to teach gender in medical school. 2018; 1-6.
[7] Pettit RK, Mccoy L, Kinney M. What millennial medical students say about flipped learning. 2017; 487-497.

[8] Hill MR, Goicochea S, Merlo LJ, et al. In their own words: stressors facing medical students in the millennial generation generation. Med Educ Online; 23. Epub ahead of print 2018. DOI: 10.1080/10872981.2018.1530558.

[9] Njie-carr VPS, Lude- E, Lee MC, et al. An integrative review of flipped classroom teaching models Elsevier B.V. Epub ahead of print 2016. DOI: 10.1016/j.profnurs.2016.07.001.

[10] Mccutcheon K, Lohan M, Traynor M, et al. S A systematic review evaluating the impact of online or blended learning vs . face-to-face learning of clinical skills in undergraduate nurse education. Epub ahead of print 2014. DOI: 10.1111/jan.12509. 